Journal of Biomedical and Pharmaceutical Research Available Online at www.jbpr.in

CODEN: - JBPRAU (Source: - American Chemical Society)

NLM (National Library of Medicine): ID: (101671502) Index Copernicus Value 2019: 90.22

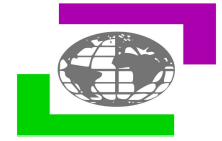

\title{
A Review on: Digitalis Purpurea
}

\section{Roshani Metkari $^{1}$, Ashwini Markad ${ }^{1}$, Poonam Bhong ${ }^{1}$, Mohini Yadav', Omkar Kolhe ${ }^{2}$}

\author{
Students ${ }^{1}$, Assistants Professor ${ }^{2}$
}

Navsahyadri Institute of Pharmacy, Pune

Article Info: Received 17 July 2021; Accepted 20 August 2021

DOI: https://doi.org/10.32553/jbpr.v10i4.876

Corresponding author: Ashwini Markad

Conflict of interest statement: No conflict of interest

\begin{abstract}
Digitalis contain cardiac glycosides and used in the treatment of congestive heart failure. Digitalis drug obtain from Digitalis Purpurea L. belongs to family scrophulariaceae. 200 years ago William Withering discover the use of digitalis in CHF treatment in 1785.In 18th century a controversy has existed about the benefits and risks of digitalis in patients with heart problems. Active component of digitalis classified as cardiac glycosides and cardiotonic steroids. The term "digitalis" or "cardiac glycosides" are used to refer to any of steroids or steroid glycosides compound which exert characteristic positively inotropic and electrophysiological effect on heart. In 20th century digitalis and its derivatives specially, digoxin is used in treatment of CHF. Cardiac glycosides are used in therapy of CHF since William Withering identify their uses. Digitalis purpurea is not only use in treatment of CHF also has wound healing, antioxidant and cytotoxic activity. In 1990 most prescribed drug is digoxin. It shows intermediate duration of action. Digoxin is use for its rate control in atrial fibrillation in the presence of marginal blood pressure. The introduction of diuretic provide an alternative more effective and safer for treatment of $\mathrm{CHF}$.
\end{abstract}

Keywords: CHF., Digitalis Purpurea L

\section{Introduction}

Digitalis is a type of cardiac glycoside. It plays important role in the congestive heart failure therapy and it was first prescribed by England physician and botanist in 18 th century monograph obtained from dried leaves of common foxgloves plants ${ }^{1}$ and containing substances that stimulate heart muscle ${ }^{3}$ (Digitalis purpurea) . Belonging to family scrophulariaceae. in $1785 .^{1}$

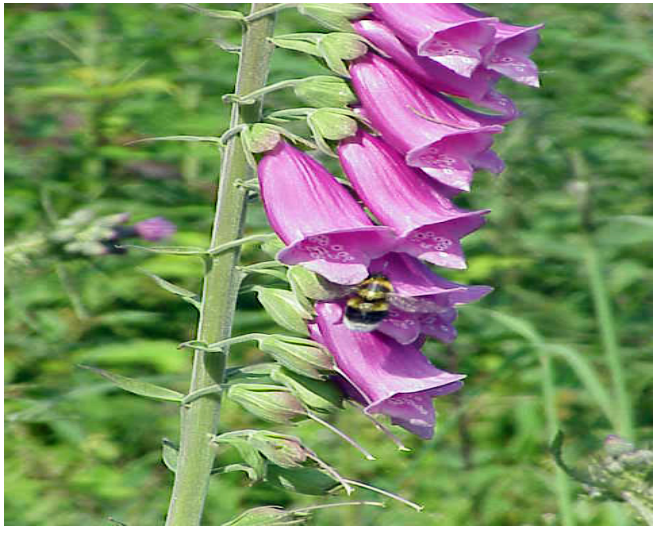

Figure 1: Digitalis (7) 
Digitalis mostly used in the patient high blood pressure and used in atherosclerosis. ${ }^{2}$ or patients with atrial fibrillation. Digitalis enhance vagal efferent activity to heart and electrical impulses passed through atrioventricular node and decrease their conduction velocity because of Para sympathomimetic activity. On the basis of these results, rate of ventricular response of atrial fibrillation is decreased. ${ }^{4}$ In 18 th century a controversy has been existed about risk and benefits of digitalis drug particularly in patients with heart problems. ${ }^{1}$ Digitalis act on sodium potassium ATPase of monocytes. ${ }^{5}$ Main chemical constitutes of digitalis are digoxin Also included. digitoxin and digitoxigenin etc. ${ }^{6}$ Detailed information about digitalis drug their sources, chemistry and structural activity relationship are involved in standard texts . ${ }^{1}$

\section{Mechanism Action Of Digitalis :-}

Digitalis act by 2 ways

(1) Positive Ionotropic effect :-

Digitalis causes a positive ionotropic effect on intact ventricle (1). Ultimately results in increase in force of contraction of heart. It inhibits the activity of myocardial SodiumPotassium-ATPase pump reversibly. The enzyme Sodium-Potassium- ATPase is an enzyme which controls the movement of Ions into the heart. Sodium-Potassium-ATPase consists of of cellular "sodium pump" in which membrane ion translocation is coupled to hydrolysis of high energy ATP phosphate(9).This enzyme also consist of alpha, beta, gamma subunits as it is called as Heterotrimer. In alpha subunit SodiumPotassium and ATP binding sites of intact enzymes are present. And for maintenance and establishment of transmembrane sodium and potassium gradient it has been effectively conserved in eukaryotes.(1). Digitalis is inhibited and binds to Sodium-PotassiumATPase pump by inhibiting Sodium-
Potassium-ATPase $\operatorname{pump}(8)$. It results in increasing the sodium and calcium concentration in the cell (12). It directly promotes entry of calcium into the cardiac cells(11) . Therefore producing a high sodium-calcium exchange. So ultimately produces intracellular calcium stores in high amount(8). It leads to higher the contractility of heart. (10). Recent study on digital confirms that immediate positive inotropic effect of cardiac glycoside (example digitalis) measured either in isometrically contracting papillary muscles strips or intact heart in a conscious dog model. Muscle strips is achieved with remarkable energy transfer efficiency and small amount of oxygen wasting (1). As decrease in ventricular filling pressure increases cardiac output. It gives positive inotropic effect (8).

(2) Av node inhibition :-

On AV node degoxin shows vagomimetic effects. In atrioventricular node it slows down electrical conduction by stimulating parasympathetic nervous system .Thus increase in calcium level, it leads to prolongation of Phase 0 and phase 4 of cardiac action potential. So that it leads to increase in AV node refractory period. As decrease AV conduction through AV node it carries a decrease in ventricular response (9).

\section{Pharmacokinetics Interaction :-}

\section{Absorption:-}

It is approximately 70 to $80 \%$ absorbed in the first part of small bowel.[14]

The bioavailability of oral dose from 50 to 60 $\%$ [14]

It is increasing age the amount of saliva produced is reduced and this can reduce the rate of drug absorption by influencing the gastric $\mathrm{pH}$.

The surface area for drug absorption is also decreased due to intestinal atrophy it is 
combined with reduced concentration gradient due to the poorer blood flow. [13]

\section{Distribution:-}

Drug administration 6 to 8 hrs tissue distribution phase is observed. [15]

Distributed widely throughout the body.

It is bound extensively to skeletal muscle. [17]

It is concentrated in tissues and therefore has a large apparent volume of distribution. [15]

It is crosses both the blood brain barrier and the placenta.

During the distribution phase. digoxin in the serum is not in equilibrium with digoxin in the tissues.[15,16]

\section{Metabolism:-}

It is about $13 \%$ of digitalis dose is found to be metabolized. [14,15]

It's metabolism is stepwise cleavage of the sugar moieties and lactone ring reductase.[16]

The cytochrome P-450 system does not play a major role in digoxin metabolism. $[15,16]$

It is does not this drug induce or inhibit the enzyme in this system.[14,15]

\section{Elimination:-}

Elimination of digitalis follows first order kinetics.[14,15]

It is 50 to 70 is excreted in entirely unchanged by the kidney.[15,16]

The half life 36 to $48 \mathrm{hrs}$ and increases case of renal impairment.

Affected by some drug interactions and diseases condition. [16]

\section{Toxicity:-}

Digitalis is a toxic plant. At low serum drug concentrations, digitalis was well tolerated. [19]
Digoxin has a very narrow therapeutic index, and its administration is subject to drug-drug interactions and comorbidities.

The following conditions indicate the use of digoxin immune fab:

-Any digoxin-related life-threatening dysarhythmia.

-Refractory hyperkalemia

-Acute ingestion of $10 \mathrm{mg}$ in adults.

-Acute ingestion of $4 \mathrm{mg}$ in children. [9]

Anorexia, nausea, and vomiting may be initial indicators of toxicity. [19]

Digitalis glyocoside are excreted slowly.

Therefore intoxication during therapy are common.

The incidence of digitalis toxicity has been estimated to range from 5 to $23 \%$. [18]

Symptoms of Digitalis poisoning include,

-low pulse rate

-nausea

-vomiting and uncoordinated contractions of different parts of the heart, leading to cardiac arrest and finally death.[19]

\section{Clinical uses:-}

1) Digitalis used in the treatment of congestive heart failure.(1)

2) Digoxin is used in treatment of atrial fibrillation. (21)

3) Digitalis having wound healing and hepatoprotective activity. (18)

4) Digoxin is used in treatment of heart failure since the publication of the DIG trail. (22)

5) Its use in therapy of systolic heart failure and supraventricular tachycardia is controversial. (8)

6) Digitalis has antioxidant and cytotoxic activity too. (1) 
7) The introduction of diuretic is an alternative safer for treatment of CHF. (20)

8) Digitalis also used in high blood pressure.

9) It also used in atherosclerosis. (2)

\section{Conclusion:-}

In short digitalis contains cardiac glycoside. It obtained from Digitalis purpurea belonging to the family scrophulariaceae. The study of digitalis says that it may increases mortality. These used in the therapy of congestive heart failure but revealed in patients with atrial fibrillation. Digoxin has been used limited because it has narrow therapeutic index. Digitalis also has wound healing antioxidants and cytotoxic activity.

\section{Reference: -}

1. Paul J. Hauptman \& Ralph A. Kelly, Digitalis 1999(3), 1265-1270, available at https://www.ahajournals.org/doi/full/10.1161 /01.cir.99.9.1265

2. https://www.britannica.com/science/phasestate-of-matter

3. Braunwald E. Cardiol J. Effect of digitalis on the normal and the failing heart, 1985 May ; 5(5suppl A): 51A-59A. available at https://pubmed.ncbi.nlm.nih.gov/3886752/

4. Gregory Curfman, MD; Digitalis Glycoside for heart rate control in atrial fibrillation, Chicago, IL 60611,-1785 available at https://jamanetwork.com/journals/jama/fullar ticle/2774389

5. Rehman R, Haio, digitalis Toxicity, 2021, 17 July pg no. 324-365 available at https://www.ncbi.nlm.nih.gov/books/NBK45 9165/\#: :text=The\%20main\%20mechanism $\% 20$ of $\% 20$ action,in $\% 20$ exchange $\% 20$ for $\% 2$ 0calcium\%20ions

6. Bhatt R, Digitalis Biological sources, medicinal uses, morphological features \& MCQs, 2020 March 7 available at https:/gpatindia.com/digitalis-biologicalsourcesmedicinal-uses-morphologicalfeatures-and-mcqs/
7. https://www.google.com/imgres?imgurl=http $\mathrm{s} \% 3 \mathrm{~A} \% 2 \mathrm{~F} \% 2 \mathrm{Fupload}$.wikimedia.org\%2Fwi kipedia\%2Fcommons\%2F7\%2F74\%2FDigit alis purpurea2.jpg\&imgrefurl $=\mathrm{https} \% 3 \mathrm{~A} \% 2$ F\%2Fen.wikipedia.org\%2Fwiki\%2FDigitalis \&docid $=-5 \mathrm{RK} 7 \mathrm{tGzO}$ (5blM\&tbnid=dxNL6K6ceWupM\&vet $=1 \&$ w $=480 \& \mathrm{~h}=640 \& \mathrm{hl}=\mathrm{en}$ IN\&source $=\mathrm{sh} \% 2 \mathrm{Fx} \% 2 \mathrm{Fim}$

8. Gorden A. Ewy, MD, Digitoxin; The art and science, Volume 128,issue 12, P1272- 1274 , Dec (1) 2015 , available at, https://www.ahajournals.org/doi/full/10.1161 /01.cir.99.9.1265

9. David M. Shetty M. Digoxin 2021, July 18; pg no. 425-430, available at https://www.statpearls.com/ArticleLibrar y/viewarticle/90909

10. Parashuraman S,Cardiac glycosids and drugs for heart failure slideshare , 2017, Sep 6. Available at https://www.slideshare.net/ParasuramanParas uraman/cardiac-glycosides-79475413

11. Mehrez S., Digitalis slideshare, 2014,July 2021, available at https://www.slideshare.net/saramehrez91/dig italis-37197968

12. Vaishnav Nikhil, Drug present on digitalis drug, slideshare 2018 Jan 18, available at https://www.slideshare.net/NikhilVaishnav3/ digitalis-nikku-ppt

13. Currie M. Wheat $M$. Kiat $H$. Pharmacokinetic consideration for digoxin in older people, 2011 Jan 15, pg no.130-135 available at https://www.ncbi.nlm.nih.gov/pmc/articles/P MC3134946/

14. https://go.drugbank.com/drugs/DB00390

15. GlaxoSmithKline, lanolin ( digoxin) Injecton pediatric $100 \mathrm{mcg}$ in $\mathrm{ml}$,NDA 09330/s- 025 Aug 2009, pg No. 3 - 19.

16. Youan BI Beniet marias, Clinical pharmacokinetics: Digoxin slideshare, 2014 July 1, available at https://www.slideshare.net/mariusbeniet3/cli nical-pharmacokinetics-of-digoxin

17. https://slidetodoc.com/drugs-for-heartfailure-angina-department-of-pharmacology/ 
18. Zahid H.Rizwani G. Digitalis Purpurea L. : A Concise Drug Review with Probable Clinical Uses, 2016 Jan, pg no. 5-12 available

at
https://www.researchgate.net/publication/318 339109_Digitalis_purpurea_L_A_Concise_D rug_Review_with_Probable_Clinical_Uses

19. Jadhav M. Singh N. elt. Digitalis Purpurea A Review on Phytochemical \& pharmacological profile, ISSN: 23483962 available at https:/ijpjournal.com/bftarticle/digitalis-purpurea-an-overview-onphytochemical-and-pharmacologicalprofile/?view=fulltext

20. Poole-Wilson P.A. Digitalis : Dead or alive, Issue at 1988, Nov11, 2008 ,Pg no.
235-254; available at https://www.karger.com/Article/Abstract/174 449

21. Whayne T.,Clinical use of Digitalis : State of the Art Review,2018,July $31 \mathrm{Pg}$ No.427-440 available at https://link.springer.com/article/10.1007/s402 56-018-0292-1

22. Goldberger Z.D.,Caleb A. elt. ,Digitalis use in contemporary clinical practice ,JAMA Intern Med. 2014(Jan),Pg No. 151-154. Available at https://jamanetwork.com/journals/jamaintern almedicine/fullarticle/1770520 